\title{
Bone scan index on bone scintigraphy and radiation therapy for bone metastases from cancers other than prostate and breast cancers: a retrospective observational study
}

Naoya Ishibashi ( $\sim$ ishibashi.naoya@nihon-u.ac.jp)

Nihon University School of Medicine

Toshiya Maebayashi

Nihon University School of Medicine

Yuki Kimura

Nihon University School of Medicine

Masahiro Okada

Nihon University School of Medicine

Research article

Keywords: bone scintigraphy, bone scan index, radiation therapy

Posted Date: April 27th, 2020

DOl: https://doi.org/10.21203/rs.3.rs-21723/v1

License: (c) (i) This work is licensed under a Creative Commons Attribution 4.0 International License.

Read Full License 


\section{Abstract \\ Background}

A low bone scan index that is associated with a better prognosis in patients with bone metastases from prostate or breast cancer, the former often being osteolytic, has been established. In this study we aimed to use new automatic analysis software (VSBONE BSI; Nihon Medi-Physics, Tokyo, Japan) to investigate whether the pre-radiation therapy bone scan index, derived from bone scintigraphy images, is a prognostic indicator in patients undergoing radiation therapy for bone metastases from cancers other than breast or prostate cancer.

\section{Methods}

In this retrospective single institution study, we analyzed data of 51 patients who had undergone wholebody scintigraphy before receiving radiation therapy for bone metastases from cancers other than breast and prostate cancer between 2013 and 2019. Their bone metastases were classified as osteoblastic, osteolytic, or mixed and their pre-radiation bone scan indexes were automatically calculated using newly developed software (VSBONE BSI; Nihon Medi-Physics, Tokyo, Japan). Univariate and multivariate analyses were performed to identify associations between selected clinical variables and overall survival.

\section{Results}

We did not find a significant association between BSI and overall survival, possibly because osteolytic lesions may be underestimated by bone scan indexes. However, we did find that younger patients (aged less than the median of 66 years at the time of bone scintigraphy or of diagnosis of bone metastases) had significantly better overall survivals than older patients ( $P=0.016$ and $P=0.036$, respectively). Additionally, bone scan indexes were significantly lower in patient with solitary or osteolytic bone metastases than in those with osteoblastic or mixed bone metastases $(P=0.035$ and $P=<0.001$, respectively), and significantly higher in those with lung cancer than in those with other types of cancer (mean BSI $3.26 \%$ vs. $1.97 \%$; $P=0.009$ ).

\section{Conclusions}

The only significant association with survival identified in this study was for age at the time of bone scintigraphy and at time of diagnosis of bone metastases. In particular, we found no association between bone scan index and survival in the whole study cohort.

\section{Background}


Bone is a common site for metastasis of malignant tumors, $50-75 \%$ of malignant tumors metastasizing to bone $(1,2)$. It has been reported that $30-40 \%$ of lung cancers metastasize to bone during their clinical course (3). The modality of choice for evaluation of the presence and extent of bone metastases is bone scintigraphy (BS) using radiopharmaceuticals such as ${ }^{99 \mathrm{~m}} \mathrm{Tc}$-labeled phosphonates or phosphates because the whole body can easily be scanned in one session. However, because radiopharmaceuticals accumulate at sites of hydroxylapatite deposition, non-metastatic bone lesions caused by trauma and degeneration can appear as hot spots $(1,4)$. In recent years, hot spots have been characterized and quantified using an artificial neural network (ANN) and an index for the total amount of bone metastases, called the bone scan index (BSI), has been developed $(5,6)$. For example, bone metastases from prostate cancer are often osteoblastic and readily appear as hot spots. Many reports on the relationship between $\mathrm{BSI}$ and prognosis indicate that the prognosis is better in patients with lower $\mathrm{BSI}(7,8,9)$. However, there have been few reports on BSI and malignant tumors other than prostate cancer. When bone metastases are detected in patients with prostate or breast cancers, the median survival is expected to be years with recent new endocrine therapy and molecular-targeted drugs. In contrast, the median survival is as short as approximately 7 months in patients with lung cancer and hepatocellular carcinoma $(10,11,12,13)$. Therefore, radiation therapy (RT) is often administered to relieve symptoms of bone metastasis from lung cancer and other cancers. In this study, we determined the pre-irradiation BSI and prognosis in patients who underwent RT for bone metastases from malignant tumors other than prostate and breast cancers, such as lung cancer and hepatocellular carcinoma. We used new analysis software VSBONE BSI (Nihon Medi-Physics, Tokyo, Japan) to automatically calculate BSI. To the best of our knowledge, this is the first time this software has been used in the clinical study.

\section{Methods}

We retrospectively reviewed relevant data of patients treated with local RT for bone metastases between 2013 and 2019, and we selected 51 patients whose bone metastases had been confirmed by computed tomography (CT) or magnetic resonance imaging (MRI) and who had also undergone BS. This study was approved by our institutional Review Board; informed consent was obtained from all patients. We have read the Declaration of Helsinki and followed its guidelines in this investigation. The clinical data of all 51 patients are summarized in Table 1. Age at the time of BS ranged from 32 to 85 years (median 66 years) and there were 33 men (64.7\%) and 18 women (35.3\%). The most common primary tumor was lung cancer (21 patients, $41.2 \%$ ) and the second most common liver (nine patients, $17.6 \%$ ). Seven patients had solitary bone metastasis (13.7\%) and 44 multiple bone metastases (86.3\%). According to the CT findings, bone metastases were classified into the following three types $(14,15)$ : osteoblastic $(n=$ $6,11.8 \%)$, osteolytic $(n=15,29.4 \%)$, and mixed $(n=30,58.8 \%)$. Concurrent visceral metastases were detected in 36 patients $(70.6 \%)$. 
Table 1

Characteristics of patients treated with radiation therapy for bone metastasis

\begin{tabular}{|ll|}
\hline Characteristics & $\mathbf{n}=51(\%)$ \\
\hline Age at the time of bone scintigraphy, median years (range) & $66(32-85)$ \\
\hline Gender & \\
\hline Male & $33(64.7)$ \\
\hline Female & $18(35.3)$ \\
\hline Primary tumor site & \\
\hline Lung & $21(41.2)$ \\
\hline Liver & $9(17.6)$ \\
\hline Kidney & $4(7.7)$ \\
\hline Bile duct & $3(5.8)$ \\
\hline Pancreas & $2(3.9)$ \\
\hline Colon & $2(3.9)$ \\
\hline Ovary & $2(3.9)$ \\
\hline Thyroid & $1(2.0)$ \\
\hline Stomach & $1(2.0)$ \\
\hline Gallbladder & $1(2.0)$ \\
\hline Uterine body & $1(2.0)$ \\
\hline Uterine cervix & $1(2.0)$ \\
\hline Bladder & $1(2.0)$ \\
\hline Bone & $1(2.0)$ \\
\hline Unknown & $1(2.0)$ \\
\hline Number of bone metastasis & $74(86.3)$ \\
\hline Solitary & \\
\hline Multiple & \\
\hline Type of bone metastasis & \\
\hline Osteoblastic & \\
\hline Osteolytic & \\
\hline \hline Abbreviations: RT, radiation therapy. & \\
\hline
\end{tabular}




\begin{tabular}{|ll|}
\hline Characteristics & $\mathbf{n = 5 1 ( \% )}$ \\
\hline Mixed & $30(58.8)$ \\
\hline Bone scan index, mean \% (range) & $2.50(0.00-11.86)$ \\
\hline Visceral metastasis & $36(70.6)$ \\
\hline Yes & $15(29.4)$ \\
\hline No & \\
\hline Systemic chemotherapy before RT & $25(49.0)$ \\
\hline Yes & $26(51.0)$ \\
\hline No & \\
\hline Performance status at RT & $33(64.7)$ \\
\hline 0,1 & $18(35.3)$ \\
\hline $2,3,4$ & $30(6-40)$ \\
\hline RT dose, median Gy (range) & \\
\hline Abbreviations: RT, radiation therapy. & \\
\hline
\end{tabular}

Bone scintigraphy

Each patient was injected with $740 \mathrm{MBq}$ of ${ }^{99 \mathrm{~m}} \mathrm{Tc}$-methylene diphosphonate (Fujifilm RI Pharma, Tokyo, Japan) or ${ }^{99 m}$ Tc-hydroxymethylene diphosphonate (Nihon Medi-Physics, Tokyo, Japan). Whole-body scintigraphy was performed $\geq 3.5$ hours after the administration, using a gamma camera at a speed of 12 or $13.3 \mathrm{~cm} / \mathrm{min}$ with a low-energy high-resolution collimator, $512 \times 1024$ or $256 \times 1024$ matrix size, zoom factor 1.00 , and $139 \mathrm{keV}$ photopeak with $20 \%$ window or $140.5 \mathrm{keV}$ photopeak with $10 \%$ window. One of the following two gamma camera units was used; Forte (Philips Japan, Tokyo, Japan) or Discovery NM/CT 670 (GE Healthcare Japan, Tokyo, Japan). Raw image data were transferred to a PC with VSBONE BSI software and analyzed.

\section{VSBONE BSI}

The database of VSBONE BSI comprises data of pairs of anterior and posterior BS images of Japanese patients with prostate cancer $(16,17)$. Additionally, skeletal segmentation from 246 patients with prostate cancer and hot spot extraction from 896 patients with prostate cancer were performed, using a butterflytype network of fully convolutional networks. Fully convolutional networks have no threshold for hot spots unlike ANN. Hot spots suspected of being metastases are depicted in red, whereas lesions suspected of being false positives are depicted in blue. From these, the BSI is automatically calculated. The BSI of the 51 patients in this study ranged from $0.00-11.86 \%$ (mean $2.50 \%$ ). 


\section{Radiation therapy}

Systemic chemotherapy was administered to 25 patients (49.0\%) after BS and prior to commencing RT. RT was performed to relieve pain or to prevent or improve spinal cord paralysis. Performance status (PS) at the start of RT was evaluated according to the Eastern Cooperative Oncology Group criteria (18). There were 33 patients with PS $\leq 1$ (68.7\%) and 18 with PS $\geq 2$ (35.3\%). Ten patients received irradiation to multiple sites in one treatment session and eight received irradiation in multiple sessions, the total RT dose ranging from 6 to $40 \mathrm{~Gy}$ (median $30 \mathrm{~Gy}$ ).

\section{Statistical analysis}

SPSS version 21.0 (IBM, Armonk, NY, USA) was used for statistical analysis. To identify variables associated with high BSI, univariate analysis with the Mann-Whitney $\mathrm{U}$ test was performed using the following patient characteristics: age at BS (median $<66$ years vs. $\geq 66$ years), sex, primary tumor site (lung cancer vs. other tumors), number of bone metastases (solitary vs. multiple), and type of bone metastasis (osteolytic vs. others). The Kaplan-Meier method was used to calculate the probability of overall survival (OS) from the date of BS. Differences in survival between subgroups of patients according to BSI (< mean $2.50 \%$ vs. $\geq$ mean), visceral or brain metastases at BS (yes vs. no), systemic chemotherapy before RT (yes vs. no), PS at RT $(0,1$ vs. 2, 3, 4), and the above mentioned variables were analyzed using Mantel's log-rank test and multivariate analyses Cox proportional hazard model. A $P$ value of $<0.05$ was considered to denote statistical significance.

\section{Results}

Univariate analysis revealed that the BSI was significantly higher in patients with lung cancer than in those with other tumors (mean BSI 3.26\% vs. 1.97\%; $P=0.009$ ) (Fig. 1 and Table 2). The BSI was significantly lower in patients with solitary and osteolytic bone metastases than in those with other types of metastases ( $P=0.035$ and $P=<0.001$, respectively) (Fig. 2 and Table 2). 
Table 2

Results of univariate analyses of associations between patient characteristics and bone scan index

\section{Patient characteristics}

BSI, mean \% (range)

P-value

Age at bone scintigraphy (years)

$\begin{array}{lll}<66 & 3.08(0.00-11.86) & 0.239 \\ \geq 66 & 1.99(0.00-5.46) & \end{array}$

Gender

Male

$2.46(0.00-11.86)$

0.430

Female

$2.57(0.29-5.46)$

Primary tumor site

Lung

$3.26(0.43-8.77)$

$0.009 *$

Others

$1.97(0.00-11.86)$

Number of bone metastasis

Solitary

$1.10(0.00-3.15)$

$0.035^{\star}$

Multiple

$2.73(0.00-11.86)$

Type of bone metastasis

Osteolytic

$1.08(0.00-5.46)$

$<0.001^{\star}$

Others

$3.10(0.38-11.86)$

Abbreviations: $\mathrm{BSI}=$ bone scan index; $\mathrm{Cl}=$ confidence interval; $\mathrm{RT}$ = radiation therapy.

*Significant difference between two groups $(P<0.05)$

Overall survival time after BS ranged from 25 days to 2113 days with a median of 221 days. A high BSI ( $\geq$ mean) was not correlated with prognosis (Fig. 3 and Table 3 ). Both univariate and multivariate analyses showed that the younger the patients were when BS was performed or bone metastases diagnosed, the better the prognosis ( $P=0.016$ and $P=0.036$, respectively) (Fig. 4 and Table 3). 
Table 3

Univariate and multivariate analyses of predictors of overall survival after radiation therapy

\section{Prognostic factors}

Univariate analysis

Multivariate analysis

$P$-value $\quad P$-value $\quad 95 \% \mathrm{Cl}$

Age at bone scintigraphy (years)
$<66$ vs. $\geq 66$
$0.016^{*}$
$0.036^{*}$
$1.052-4.696$
Gender
0.271
0.599
$0.384-1.737$

Primary tumor site

Lung cancer vs. Others

0.818

0.560

$0.342-1.788$

Number of bone metastasis

Solitary vs. Multiple

0.565

0.342

$0.260-1.597$

Type of bone metastasis

Osteolytic vs. Others

0.843

0.823

$0.472-2.570$

Bone scan index

$<2.50 \%$ vs. $\geq 2.50 \%$

0.322

0.908

$0.387-2.325$

Visceral metastasis

Yes vs. No

0.263

0.219

$0.757-3.370$

Chemotherapy before RT

Yes vs. No

0.580

0.674

$0.434-1.716$

Performance status at RT

0,1 vs. $2,3,4$

0.124

0.067

$0.231-1.052$

Abbreviations: $\mathrm{Cl}=$ confidence interval; $\mathrm{RT}$ = radiation therapy. ${ }^{*}$ Significantly different $(\mathrm{P}<0.05)$

\section{Discussion}

Bone metastases often occur in patients with prostate or breast cancer. Postmortem examination reportedly reveals bone metastases in $68 \%$ of patients with prostate cancer and $73 \%$ of those with breast cancer (19). In particular, bone metastases in patients with prostate cancer tend to be osteoblastic and are highly detectable as hot spots on BS $(1,20)$. BSI was first developed for characterization and quantitation of these hot spots, and a method using ANN, which was trained on a patients' database, was established $(5,21)$. In Japan, BONENAVI software (Fujifilm RI Pharma) was developed using ANN trained on a database of Japanese patients with prostate cancer (22). BONENAVI BSI automatically detects hot spots and makes calculations by combining abnormal areas with a high probability of representing 
metastases. Recently, databases of Japanese patients with breast cancer and lung cancer have been added and reported to show good accuracy (23). In this study, we used VSBONE BSI, new analysis software, to automatically calculate of BSI for the first time, to the best of our knowledge. VSBONE BSI software also uses ANN trained on databases of Japanese patients and automatically calculates BSI on the basis of the same basic principles as does BONENAVI BSI $(16,17)$. In this study of patients with cancers other than prostate and breast cancers, BSI was significantly higher in those with bone metastases from lung cancer than in those with bone metastases from other malignant tumors. In general, metastases from other malignant tumors including hepatocellular carcinoma, are predominantly osteolytic, whereas metastases from lung cancer are more likely to have increased hydroxylapatite deposition. In this study, there were patients with BSI $0.00 \%$ despite multiple bone metastases from hepatocellular carcinoma having been identified by CT. Possible reported explanations for bone metastases not being detected by BSI are that $2.4 \%$ of bone metastases from hepatocellular carcinoma are osteolytic and there are soft tissue components in $38 \%$ of patients $(13,24)$. Our finding of significantly lower BSI with osteolytic lesions in this study is consistent with past reports that BONENAVI BSI of mild osteoblastic lesions from prostate, breast, and lung cancers are significantly lower than osteoblastic or mixed types metastases (14).

Many studies have reported that high BSI is a poor prognostic factor in patients with castration-resistant prostate cancer $(4,7,9)$. Some studies have also reported that multiple bone metastases from lung and other cancers have a poorer prognosis than solitary bone metastases $(12,25)$. We found no correlation between BSI and prognosis in patients in this study, including those with lung cancer; however, osteolytic lesions may have been underestimated.

Few studies have been conducted on BS and RT to date. As for imaging modalities used to evaluate metastatic lesions before treatment with RT for bone metastases, no difference in therapeutic effects between BS, MRI, and ${ }^{18}$ fluorodeoxyglucose positron emission tomography have been reported (26). We have reported, we believe for the first time, that age at the time of BS is a significant favorable prognostic factor for RT for bone metastases, suggesting that long-term survival may be expected even in young patients with high BSI. For example, radium-223 (Xofigo; Bayer Pharmaceuticals, Whippany, NJ, USA), which is incorporated into newly formed osteoblastic bone matrix, is associated with longer survival in patients with bone metastases from prostate cancer (27). If radium-223 is approved for treating bone metastases from malignant tumors other than prostate cancer and covered by health insurance in Japan, we can expect prolongation of survival in patients with lung cancer and high BSI.

\section{Conclusions}

The only significant association with survival identified in this study was for age at the time of bone scintigraphy and at time of diagnosis of bone metastases. In particular, we found no association between bone scan index and survival in the whole study cohort.

\section{Abbreviations}


ANN: artificial neural network; BS: bone scintigraphy; BSI: bone scan index; CT, computed tomography; $\mathrm{MRI}$, magnetic resonance imaging; RT, radiation therapy.

\section{Declarations}

Ethics approval and consent to participate

Not applicable.

\section{Consent for publication}

Not applicable.

\section{Availability of data and material}

The dataset used during this study are available from the corresponding author on reasonable request.

\section{Competing interests}

Drs. Ishibashi, Maebayashi, Kimura, and Okada declare that they have no competing interests.

\section{Funding}

No funding was received specifically for this work.

\section{Authors' contributions}

$\mathrm{Nl}$ collected the patients' data and treated the patients and was a major contributor to writing the manuscript. YK and MO interpreted the BS images. TM treated the patients. All authors read and approved the final manuscript.

\section{Acknowledgement}

We thank Dr Trish Reynolds, MBBS, FRACP, from Edanz Group (www.edanzediting.com/ac) for editing a draft of this manuscript. 


\section{References}

1. Davila D, Antoniou A, Chaudhry MA. Evaluation of osseous metastasis in bone scintigraphy. Semin Nucl Med. 2015;45(1):3-15.

2. Tofe AJ, Francis MD, Harvey WJ. Correlation of neoplasms with incidence and localization of skeletal metastases: An analysis of 1,355 diphosphonate bone scans. J Nucl Med. 1975;16(11):986-9.

3. Coleman RE. Metastatic bone disease: clinical features, pathophysiology and treatment strategies. Cancer Treat Rev. 2001;27(3):165-76.

4. Nakajima K, Edenbrandt L, Mizokami A. Bone scan index: A new biomarker of bone metastasis in patients with prostate cancer. Int J Urol. 2017;24(9):668-73.

5. Erdi YE, Humm JL, Imbriaco M, Yeung H, Larson SM. Quantitative bone metastases analysis based on image segmentation. J Nucl Med. 1997;38(9):1401-6.

6. Imbriaco M, Larson SM, Yeung HW, Mawlawi OR, Erdi Y, Venkatraman ES, Scher HI. A new parameter for measuring metastatic bone involvement by prostate cancer: the Bone Scan Index. Clin Cancer Res. 1998;4(7):1765-72.

7. Dennis ER, Jia X, Mezheritskiy IS, Stephenson RD, Schoder H, Fox JJ, Heller G, Scher HI, Larson SM, Morris MJ. Bone scan index: a quantitative treatment response biomarker for castration-resistant metastatic prostate cancer. J Clin Oncol. 2012;30(5):519-24.

8. Poulsen MH, Rasmussen J, Edenbrandt L, Høilund-Carlsen PF, Gerke O, Johansen A, Lund L. Bone Scan Index predicts outcome in patients with metastatic hormone-sensitive prostate cancer. BJU Int. 2016;117(5):748-53.

9. Uemura K, Miyoshi Y, Kawahara T, Yoneyama S, Hattori Y, Teranishi J, Kondo K, Moriyama M, Takebayashi S, Yokomizo Y, et al. Prognostic value of a computer-aided diagnosis system involving bone scans among men treated with docetaxel for metastatic castration-resistant prostate cancer. BMC Cancer. 2016;16:109.

10. Kadomoto S, Yaegashi H, Nakashima K, lijima M, Kawaguchi S, Nohara T, Shigehara K, Izumi K, Kadono Y, Nakajima K, et al. Quantification of Bone Metastasis of Castration-resistant Prostate Cancer After Enzalutamide and Abiraterone Acetate Using Bone Scan Index on Bone Scintigraphy. Anticancer Res. 2019;39(5):2553-9.

11. Dickler MN, Barry WT, Cirrincione CT, Ellis MJ, Moynahan ME, Innocenti F, Hurria A, Rugo HS, Lake DE, Hahn O, et al. Phase III Trial Evaluating Letrozole As First-Line Endocrine Therapy With or Without Bevacizumab for the Treatment of Postmenopausal Women With Hormone Receptor-Positive Advanced-Stage Breast Cancer: CALGB 40503 (Alliance). J Clin Oncol. 2016;34(22):2602-9.

12. Sugiura $H$, Yamada K, Sugiura T, Hida T, Mitsudomi T. Predictors of survival in patients with bone metastasis of lung cancer. Clin Orthop Relat Res. 2008;466(3):729-36.

13. He J, Zeng ZC, Tang ZY, Fan J, Zhou J, Zeng MS, Wang JH, Sun J, Chen B, Yang P, et al. Clinical features and prognostic factors in patients with bone metastases from hepatocellular carcinoma receiving external beam radiotherapy. Cancer. 2009;115(12):2710-20. 
14. Isoda T, BaBa S, Maruoka Y, Kitamura Y, Tahara K, Sasaki M, Hatakenaka M, Honda H. Influence of the Different Primary Cancers and Different Types of Bone Metastasis on the Lesion-based Artificial Neural Network Value Calculated by a Computer-aided Diagnostic System, BONENAVI, on Bone Scintigraphy Images. Asia Ocean J Nucl Med Biol. 2017;5(1):49-55.

15. Roodman GD. Mechanisms of bone metastasis. N Engl J Med. 2004;350(16):1655-64.

16. Shimizu A, Wakabayashi H, Kanamori T, Saito A, Nishikawa K, Daisaki H, Higashiyama S, Kawabe J. Automated measurement of bone scan index from a whole-body bone scintigram. Int J Comput Assist Radiol Surg. 2020;15(3):389-400.

17. Shimizu A, Wakabayashi H, Kanamori T, Saito A, Nishikawa K, Daisaki H, Higashiyama S, Kawabe J. Correction to: Automated measurement of bone scan index from a whole-body bone scintigram. Int J Comput Assist Radiol Surg. 2020;15(3):401.

18. Oken MM, Creech RH, Tormey DC, Horton J, Davis TE, McFadden ET, Carbone PP. Toxicity and response criteria of the Eastern Cooperative Oncology Group. Am J Clin Oncol. 1982;5(6):649-55.

19. Coleman RE. Clinical features of metastatic bone disease and risk of skeletal morbidity. Clin Cancer Res. 2006; 12(20 Pt 2): 6243s-6249 s.

20. Even-Sapir E. Imaging of malignant bone involvement by morphologic, scintigraphic, and hybrid modalities. J Nucl Med. 2005;46(8):1356-67.

21. Sadik M, Jakobsson D, Olofsson F, Ohlsson M, Suurkula M, Edenbrandt L. A new computer-based decision-support system for the interpretation of bone scans. Nucl Med Commun. 2006;27(5):41723.

22. Takahashi Y, Yoshimura M, Suzuki K, Hashimoto T, Hirose H, Uchida K, Inoue S, Koizumi K, Tokuuye $\mathrm{K}$. Assessment of bone scans in advanced prostate carcinoma using fully automated and semiautomated bone scan index methods. Ann Nucl Med. 2012;26(7):586-93.

23. Nakajima K, Nakajima Y, Horikoshi H, Ueno M, Wakabayashi H, Shiga T, Yoshimura M, Ohtake E, Sugawara $\mathrm{Y}$, Matsuyama $\mathrm{H}$, et al. Enhanced diagnostic accuracy for quantitative bone scan using an artificial neural network system: a Japanese multi-center database project. EJNMMI Res. 2013;3(1):83.

24. Seo HJ, Choi YJ, Kim HJ, Jeong YH, Cho A, Lee JH, Yun M, Choi HJ, Lee JD, Kang WJ. Evaluation of Bone Metastasis from Hepatocellular Carcinoma Using (18)F-FDG PET/CT and (99 m)Tc-HDP Bone Scintigraphy: Characteristics of Soft Tissue Formation. Nucl Med Mol Imaging. 2011;45(3):203-11.

25. Katagiri H, Takahashi M, Wakai K, Sugiura H, Kataoka T, Nakanishi K. Prognostic factors and a scoring system for patients with skeletal metastasis. J Bone Joint Surg Br. 2005;87(5):698-703.

26. Wada Y, Anbai A, Kumagai S, Okuyama E, Hatakeyama K, Takagi N, Hashimoto M. Effect of the types of pretreatment imaging modalities on the treatment response to palliative radiation for painful bone metastases from solid cancer: a single-center retrospective analysis. Radiat Oncol. 2019;14(1):98.

27. Sartor O, Coleman R, Nilsson S, Heinrich D, Helle SI, O'Sullivan JM, Fosså SD, Chodacki A, Wiechno P, Logue $\mathrm{J}$, et al. Effect of radium-223 dichloride on symptomatic skeletal events in patients with 
castration-resistant prostate cancer and bone metastases: results from a phase 3, double-blind, randomised trial. Lancet Oncol. 2014;15(7):738-46.

\section{Figures}

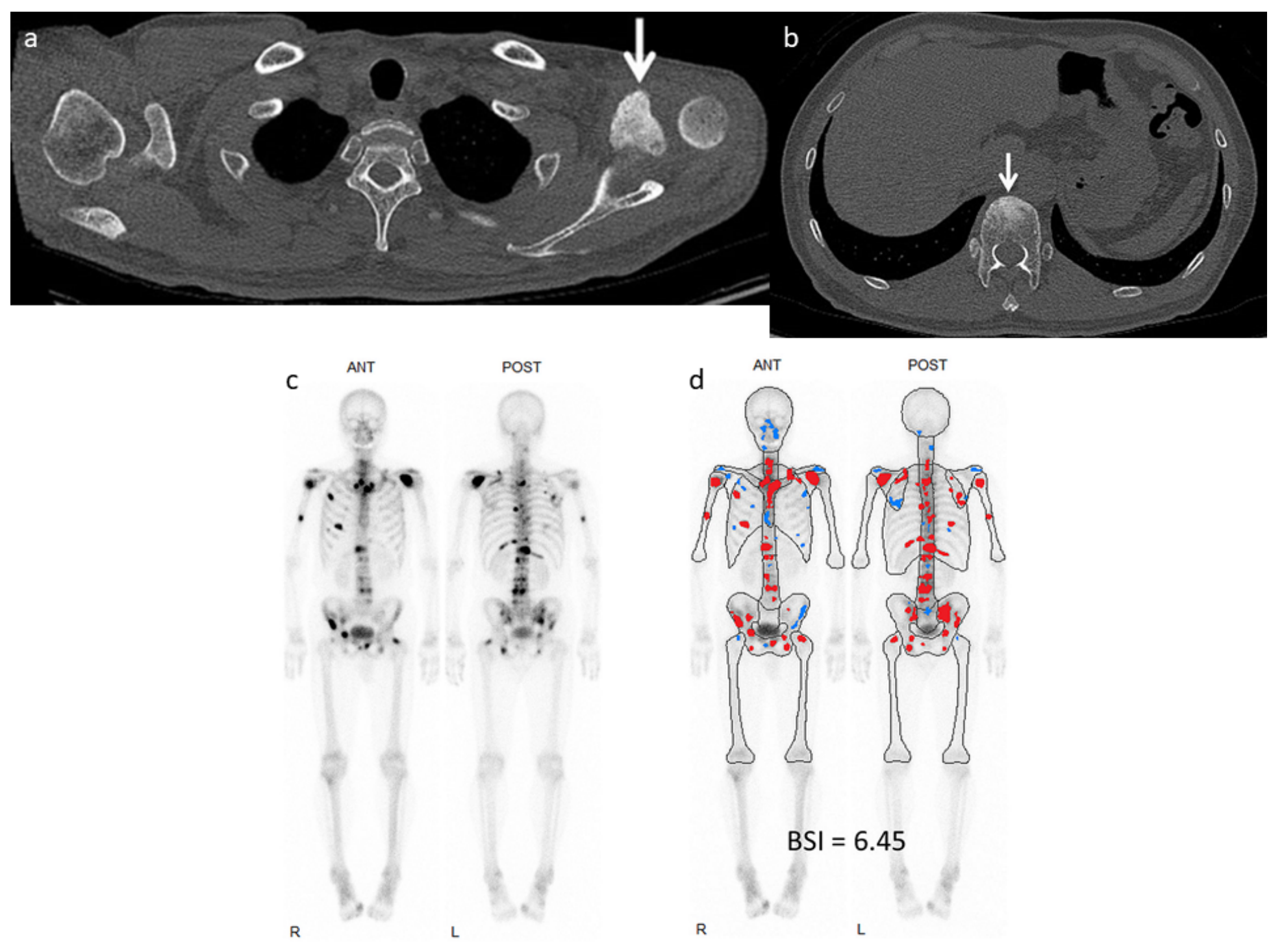

\section{Figure 1}

Representative example of a 62-year-old man with lung cancer and multiple bone metastases. Computed tomography showed multiple osteoblastic lesions $(a, b)$. Bone scintigraphy showed multiple hot spots (c) and VSBONE BSI showed these lesions as red and blue. The BSI was extreme high at $6.45 \%$ (d). 

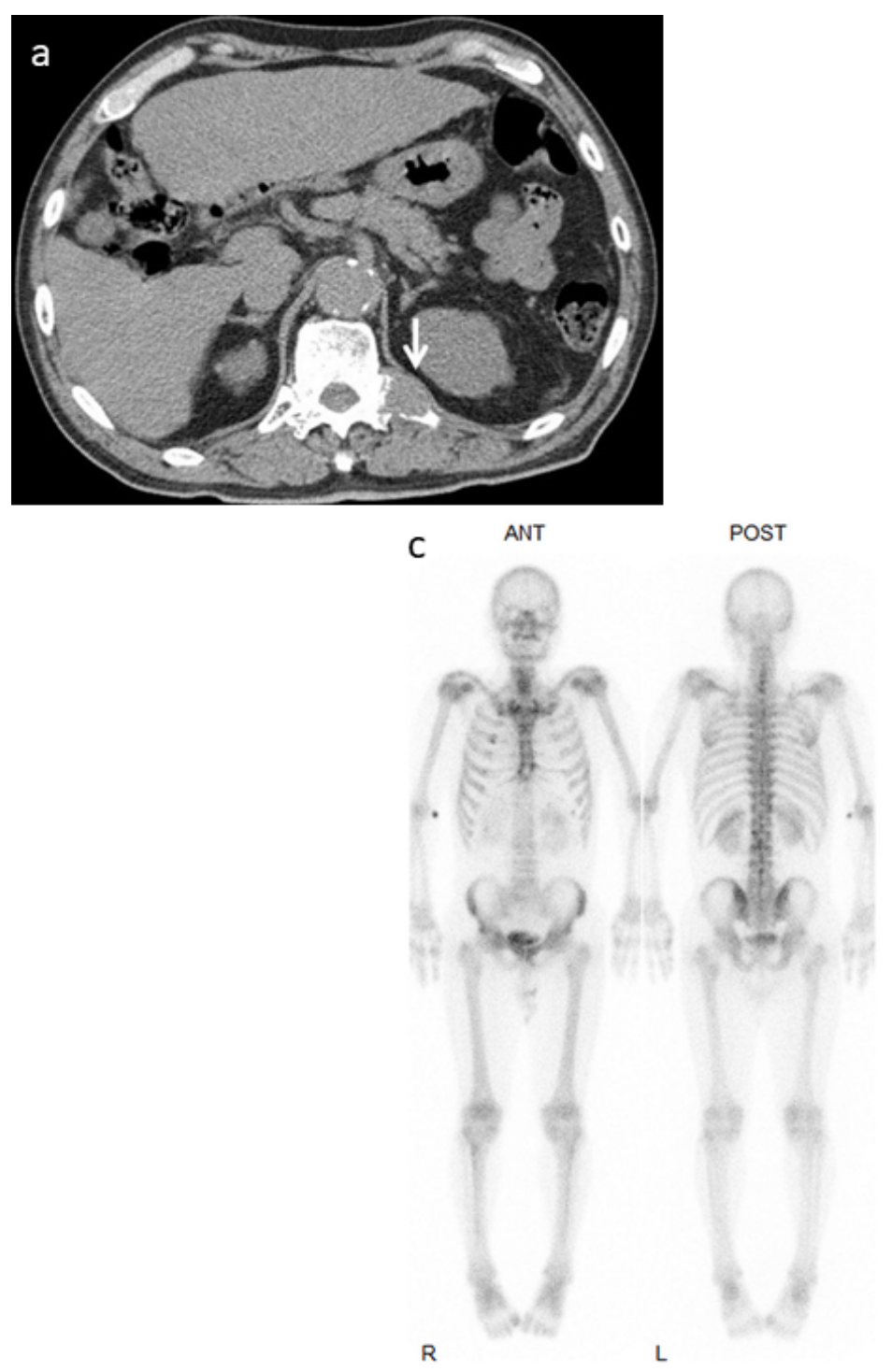

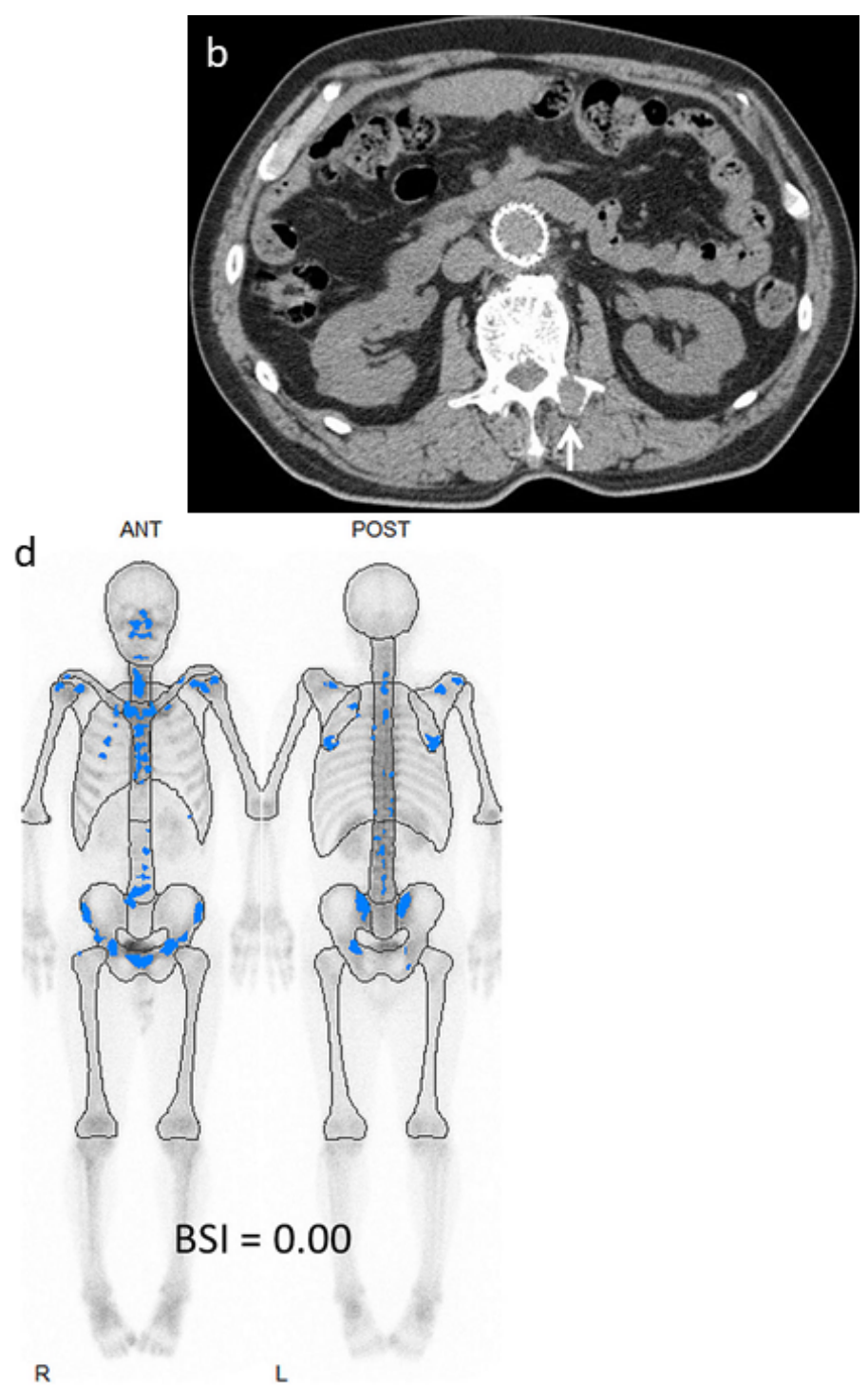

Figure 2

Representative example of a 76-year-old man with hepatocellular carcinoma and multiple bone metastases. Computed tomography showed multiple osteolytic soft tissue masses $(a, b)$. Bone scintigraphy failed to detect these lesions (c) and VSBONE BSI showed hot spots as blue only. The BSI was undetectable at $0.00 \%$ (d). 


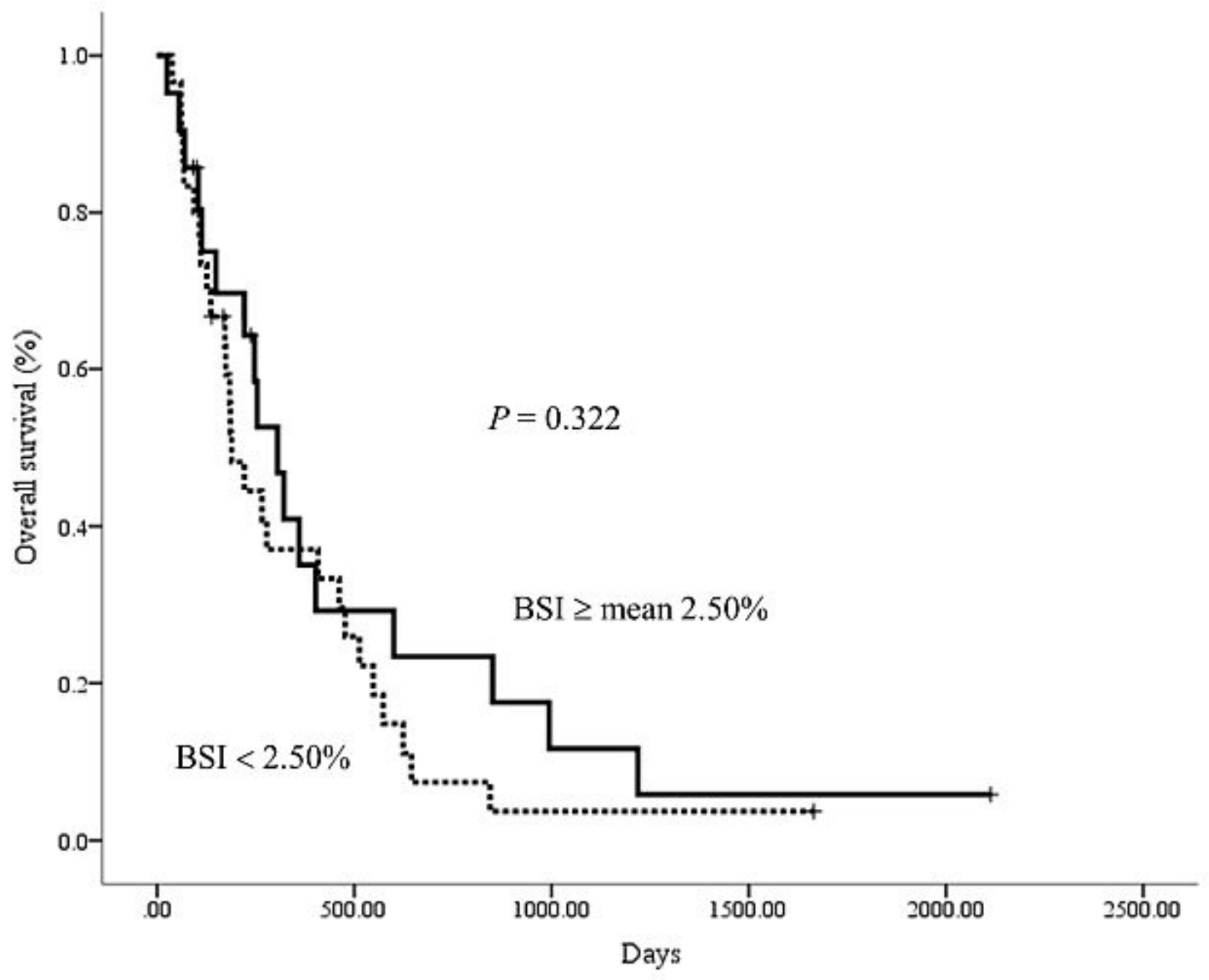

Figure 3

Kaplan-Meier survival curves of patients with $\mathrm{BSI}<$ mean $2.50 \%$ or $\geq$ mean. The difference between the two groups is not statistically significant $(P=0.322)$. 


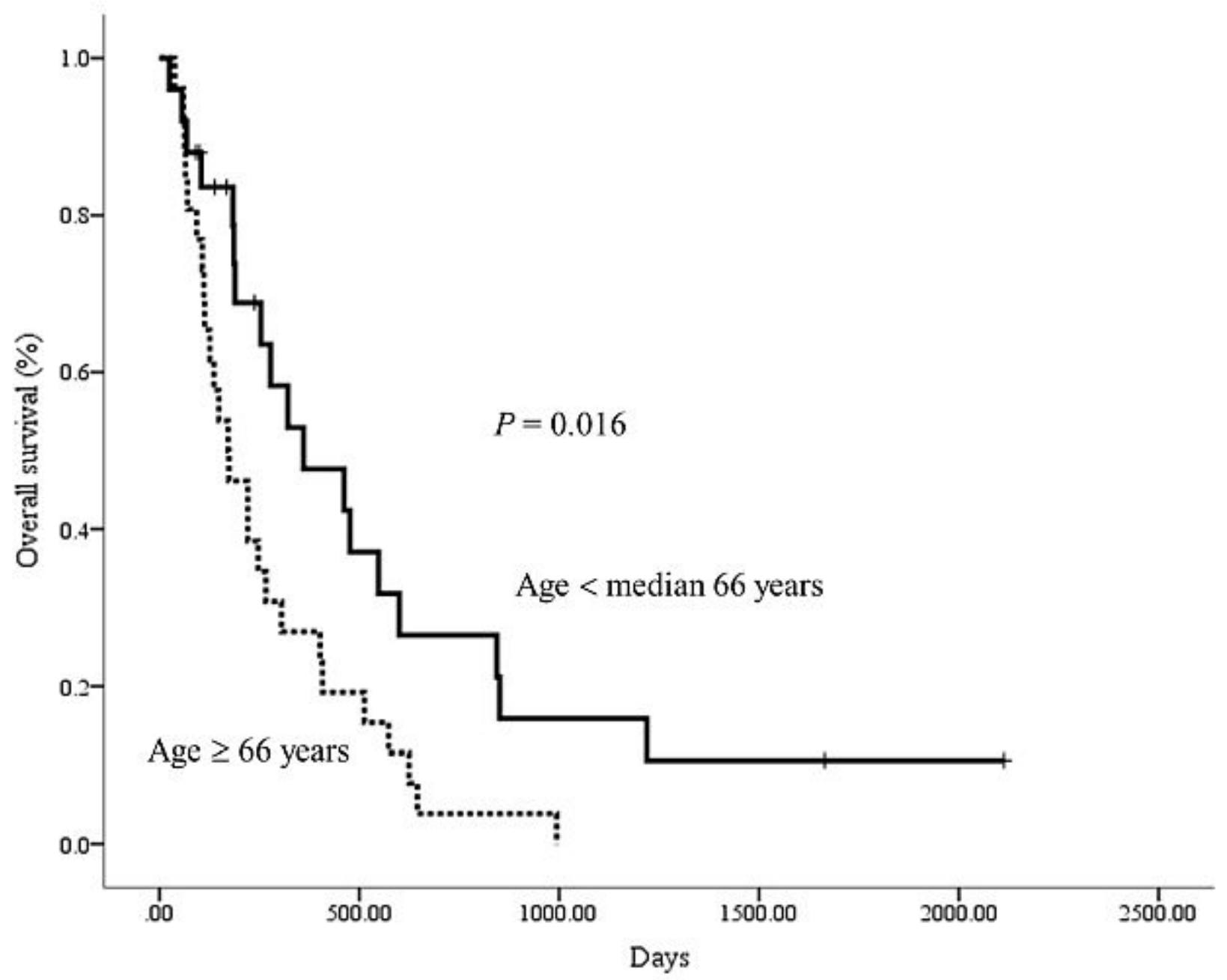

Figure 4

Kaplan-Meier survival curves of patients aged $<$ median 66 years or $\geq$ median at the time of bone scintigraphy. Survival was significantly longer in younger patients $(P=0.016)$. 